\title{
REVIEW
}

\section{Management of Fibromyalgia Syndrome: Review of Evidence}

\author{
Akiko Okifuji $\cdot$ Bradford D. Hare
}

To view enhanced content go to www.paintherapy-open.com

Received: April 19, 2013 / Published online: September 21, 2013

(c) The Author(s) 2013. This article is published with open access at Springerlink.com

\section{ABSTRACT}

Fibromyalgia syndrome (FMS) is a common chronic musculoskeletal pain disorder of unknown etiology and characterized by generalized body pain, hyperalgesia, and other functional and emotional comorbidities. Despite extensive research, no treatment modality is effective for all FMS patients. In this paper, we briefly review the history of FMS and diagnostic criteria, and potential pathophysiological mechanisms including central pain modulation, neurotransmitters, sympatho-adrenal and hypothalamic-pituitary-adrenal systems and peripheral muscle issues. The primary focus of the paper is to review treatment options for managing fibromyalgia symptoms. We

A. Okifuji $(\square)$. B. D. Hare

Department of Anesthesiology,

Pain Research Center, Pain Management Center, University of Utah, Salt Lake City, UT, USA

e-mail: Akiko.Okifuji@hsc.utah.edu

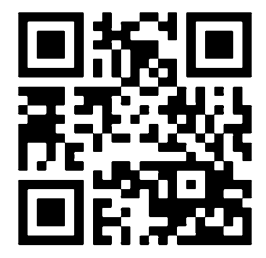

Enhanced content for this article is available on the journal web site: www.paintherapy-open.com will discuss FDA-approved medications and other pharmacologic agents, and nonpharmacologic treatments that have shown promising effects.

Keywords: Classification criteria; Duloxetine; Fibromyalgia; Milnacipran; Non-pharmacologic treatment; Pain; Pharmacologic treatment; Pregabalin

\section{INTRODUCTION}

Fibromyalgia syndrome (FMS) is a prevalent musculoskeletal pain disorder. The cardinal features are generalized body pain and hyperalgesic responses [1]. FMS patients also commonly present a range of functional disturbances, including persistent fatigue, dysregulated sleep, cognitive slowness, functional bowel disorder, paresthesia, and mood disturbance [1]. An earlier study [2] estimated the prevalence rate at $3-5 \%$ in North America. The National Arthritis Data Working group has estimated that up to 5 million people in the US suffer from FMS [3]. 


\section{History}

FMS is not a new disorder. One of the earliest descriptions can be found in the mid-ninth century in Germany when a cluster of FMS symptoms was collectively labeled as "Muskelschwiele" (muscle callus) and considered as generalized body tenderness with rheumatism [4]. The term "fibrositis" appeared in the early 1900 s to describe the condition, with inflammation of the connective tissues assumed to be the underlying pathophysiology [5]. The assumption persisted until systematic scientific studies began to appear in the literature in the 1970s, when an underlying inflammation was ruled out and a more neutral term fibromyalgia proposed [6, 7]. Several criteria, based on common clinical presentations, were delineated in the 1970s and 1980s (e.g., [8, 9]), stimulating a proliferation of research in the field. However, these criteria were rarely applied consistently and the lack of standardization made integration of the study findings very difficult.

\section{Diagnostic Criteria}

In the late 1980s, a multicenter study was conducted with the intention of developing empirically derived classification criteria for FMS [1]. The study included approximately 300 patients with FMS and 285 controls with other (non-FMS) painful conditions. Comparison of a number of FMS-related variables revealed two criteria with good sensitivity and specificity that can differentiate between the two groups. These criteria, generally referred as the American College of Rheumatology (ACR) criteria, consist of (1) a history of widespread pain of 3 months or longer duration and (2) presence of pain responses at least 11 of 18 designated tender points (TPs) [1].

Since publication in 1990, the ACR criteria have become a standard in FMS research. They have been used by the vast majority of published reports on FMS to date, creating some cohesiveness in the literature. However, the ACR criteria are not free from criticisms. One of the major issues is the validity of the TP criterion; specifically, it is not clear what the number of positive TPs actually measures. It is possible that pain response to digital pressure to the TPs may represent the underlying central dysfunction of nociceptive processing, leading to diffuse hyperalgesia. However, the number of painful TPs has been found to be the parameter most associated with psychological distress [1012], although pain sensitivity in the TPs seems relatively independent of distress [11]. Furthermore, central sensitization is not FMSspecific. Patients with various other chronic pain states, including those with localized pain, exhibit evidence that central sensitization plays an important role in their disorder [13]. In addition, there are a large number of individuals who report chronic widespread pain (CWP) without having 11 painful TPs, yet exhibit clinical and functional presentations very similar to FMS [14]. There is no clear understanding of whether the presence of 11 or more TPs represents any clinical significance or relevance to FMS. Altogether, the validity of the TP count criterion is yet to be determined.

Another concern regarding the ACR criteria is the lack of consideration of common symptoms and dysfunctions. Chronic fatigue and sleep problems are ubiquitous in FMS patients; however, they were not included in the ACR criteria because they are also commonly experienced by other patients with chronic pain and thus yielded unsatisfactory 
discriminability. However, those symptoms are common enough to be characteristics of the disorder yet not a part of the diagnostic criteria; this is a stark contrast with other syndromes such as depression where a diagnosis relies on the presence of multiple common clinical phenomena.

However, there is no question that the ACR classification criteria provided much-needed consistency in defining fibromyalgia for research studies. Unfortunately, the clinical utility of the ACR criteria is quite limited [15] and the concordance between the ACR criteria and clinical diagnosis is rather poor [16]. In order to address these concerns, new diagnostic criteria for FMS were proposed recently, based on data from another multicenter study [17]. The new criteria involve the assessment by clinicians of common symptoms such as fatigue, unrefreshed wakening and cognitive symptoms. The authors of the 2010 ACR criteria specifically note that these new classification criteria are not intended to replace the 1990 ACR classification criteria, but to be used as a clinical tool in primary care and specialized clinics. Eliminating the need to perform a physical examination for the new criteria would facilitate the use of the standardized measure to diagnose fibromyalgia in clinical settings. Furthermore, for certain research studies, such as a large epidemiological project where conducting TP examination is not feasible, the new criteria will provide a degree of standardization in the study samples. The details of the ACR criteria are listed in Table 1.

\section{Pathophysiology}

The etiology of FMS is unknown. However, accumulated evidence over the past 40 years suggests that several factors potentially underlie the disorder. Although the focus of this paper is primarily on the management of FMS, we will briefly review the literature, including the role of central pain modulation processes, muscle abnormality, neuroendocrine regulation, and sleep.

\section{Central Pain Modulation}

Research has consistently shown that FMS is associated with increased pain sensitivity that suggests dysregulation of the pain modulation process at the central level. As compared to healthy subjects, FMS patients exhibit lower pain thresholds to various types of experimentally induced noxious stimuli [1821]. FMS is also associated with increased windup (WU) sensitivity (heightened pain perception when noxious stimuli are repeatedly presented) [22]. Cortical activities in response to noxious stimulation are exaggerated in patients with FMS [19, 23, 24].

\section{Neurotransmitters}

Low levels of serotonin (5-hydroxytryptamine) activity in FMS have been shown via decreased plasma tryptophan [25], serum serotonin [26], transfer ratio of tryptophan [27], and reuptake site density [28]. Research also points to a dysregulated dopaminergic system. FMS patients show an augmented prolactin response to a buspirone challenge test, suggesting an increased sensitivity or density of dopamine D2 receptors [29]. Positron emission tomography L-DOPA uptake studies also implicate disrupted presynaptic dopamine activities [30].

\section{Sympatho-Adrenal (SA) and Hypothalamic- Pituitary-Adrenal (HPA) Systems}

A large volume of evidence exists suggesting that patients with FMS show hyporeactive SA and HAP response to a wide range of stressors including exercise $[31,32]$. FMS is also 


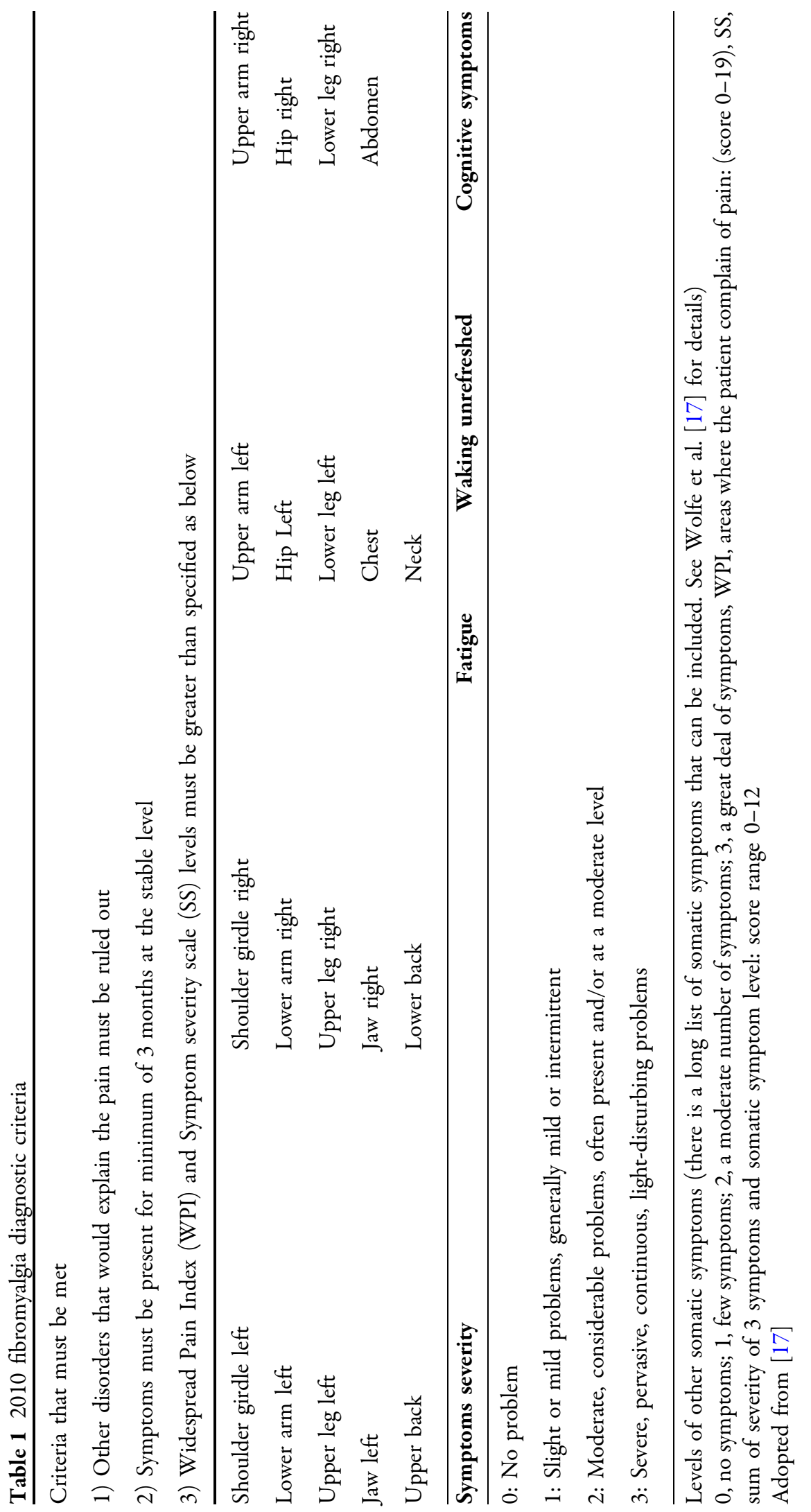


associated with altered basal catecholamine levels, independent of depression [33, 34], as well as abnormal reactivity of the HPA, such as abnormal adrenocorticotropic hormone (ACTH) levels, hypoglycemia and blunted cortisol response [35, 36]. Overall, these studies suggest the presence of hyperactive sympathetic activity with hyporeactive response to stress [37-40]. Furthermore, alteration of adrenergic gene polymorphisms seems to be present in FMS patients [41, 42]. Research indicates that there is a specific function-altering beta-adrenergic gene polymorphism in FMS patients [43], and they show a significant increase in gene expression of adrenergic molecular receptors in response to exercise, as well as at rest, as compared to healthy controls [44, 45], implicating a genetic vulnerability in at least some FMS patients.

\section{Muscular Abnormalities and Peripheral Pain Modulation}

Although an early study found abnormal biopsy results in the painful muscles in FMS patients [46], the investigation of local muscle tissue has yielded conflicting results. In general, evidence supporting the microscopic evidence of definitive pathology in the muscle tissues in FMS is scarce [47]. However, a peripheral abnormality, albeit limited, may contribute to FMS pathophysiology. For example, affected (i.e., painful) muscles of FMS patients show hypoxia [48]. Some studies using P-31 magnetic resonance spectroscopy $[49,50]$ have also shown reduced levels of adenosine triphosphate and phosphocreatine in FMS, suggesting that these metabolic abnormalities may contribute to muscle weakness and fatigability in FMS. Decreased muscle blood flow, as compared to healthy individuals, has also been shown [51]. Problems with muscular vasoconstriction (e.g., Raynaud's syndrome) are common in FMS [52]. These results suggest that peripheral ischemia may contribute to muscle pain. Furthermore, a significantly greater number of active myofascial trigger points in the trapezius muscles are found in FMS patients relative to healthy people [53]. The number of active trigger points seems to be related to diffuse mechanical hyperalgesia in FMS [54], suggesting that peripheral noxious inputs play a critical role; peripheral abnormality may create a biochemical environment that contributes to local sensitization, leading to central pain sensitivity [55].

\section{TREATMENT OF FMS}

Over the past four decades, a large variety of modalities have been tested for treating FMS. Overall, no single modality has been found to be universally effective for all FMS patients, or all FMS symptoms in an individual patient. Below, we will review commonly used FMS treatments as well as some treatments that have attracted much public attention.

\section{Pharmacologic Options}

\section{FDA-Approved Agents}

There are three medications that were approved by the federal drug administration (FDA) to treat FMS. Pregabalin, a $\gamma$-aminobutyric acid (GABA) analog and antiepileptic agent, was the first to be approved, in 2007. A multicenter, double-blind, randomized controlled trial (RCT) was conducted in 750 patients who were randomized to receive pregabalin 300,450 or $600 \mathrm{mg}$ per day or placebo for 14 weeks; significant improvement in pain and other functional measures was achieved in all the pregabalin groups as compared to the placebo group [56]. A systematic review evaluating the efficacy of pregabalin [57] found a benefit of 
pregabalin relative to placebo in pain reduction, improvement in sleep and quality of life measures (except for mood variables). A meta-analysis of 4 RCTs with more than 3,000 patients has shown that a $30 \%$ pain reduction was reported by $40 \%$ of patients receiving pregabalin versus $28 \%$ of those receiving placebo [58].

One of the common criticisms of a pharmacologic RCT is the lack of long-term follow-ups. Recently, Arnold et al. [59] published data from the open-label extension studies from the pregabalin RCT with a total of 1,207 patients who were treated for up to a year, in order to assess the long-term tolerability profile and maintenance of pain reduction. Approximately $81 \%$ of patients completed treatment. On average, the pain reduction observed in the RCT was maintained throughout the treatment period and the tolerability profile was comparable to that seen in the RCT.

There are two other medications, both serotonin norepinephrine reuptake inhibitors (SNRIs), approved by the FDA to treat FMS. Duloxetine was approved in 2008 and milnacipran in 2009. Double-blind RCTs evaluating duloxetine doses ranging between 60 and $120 \mathrm{mg}$ per day have typically shown greater improvement in pain reports and self-report functioning than those in the placebo arm [60-62]. Analysis of pooled data from the 4 RCTs [63] indicates that $48 \%$ of treated patients and $32 \%$ of patients receiving placebo reported $>30 \%$ pain reduction. Secondary analyses have shown that duloxetine was beneficial for reducing fatigue in FMS [64]. An extension trial [65] of up to 1 year showed comparable tolerability and maintenance of pain reduction. However, a recent trial with duloxetine $30 \mathrm{mg}$ failed to show improvement in pain severity relative to placebo, mostly due to the marked placebo effects [66], consistent with the earlier finding that $20 \mathrm{mg}$ duloxetine did not improve pain [62]. Similarly, double-blind RCTs [67-69] evaluating milnacipran (100-200 mg daily) showed significant improvement in pain reports and a range of symptoms as compared to placebo. Pooled data from 2 RCTs [70] showed approximately $52-61 \%$ of treated patients reporting $>30 \%$ pain reduction, versus $36 \%$ of the placebo group. A recent update of the 3-year open-label study [71] suggests that the clinical benefit is sustained during the long-term treatment.

A comparative evaluation of pregabalin, milnacipran and duloxetine [72] showed similar efficacy of the three drugs with regard to pain reduction. However, there were some differences in the secondary outcome measures and adverse effects, suggesting that these differences may guide a clinical decision as to which of these agents to use for a particular patient.

One of the concerns with these trials is the relatively high placebo response rates. For the purpose of illustration, Fig. 1 shows the results (\% of patients reporting $>30 \%$ pain reduction)

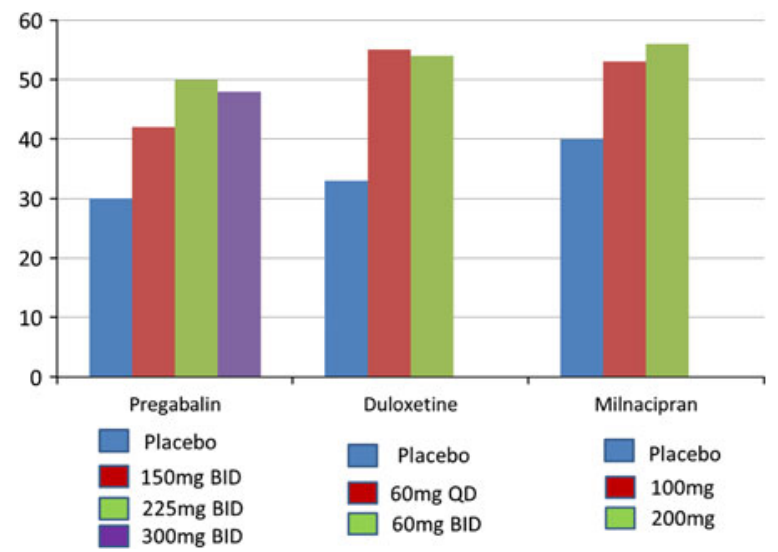

Fig. 1 Percentage of patients reporting $>30 \%$ pain reduction by dose for pregabalin [56], duloxetine [60], and milnacipran [69] versus placebo. BID twice daily, $Q D$ every day 
from the 3 trials $[56,60,69]$ by dose. A recent analysis [73] of data from 18 placebo-controlled trials in over 3,500 patients estimates that approximately $50 \%$ of treatment in response to these drugs can be attributed to placebo effects.

\section{Other Pharmacologic Treatments}

Sodium Oxybate Sodium oxybate is a commercially produced form of the sodium salt of $\gamma$-hydroxybutyric acid (GHB). It has been approved by the FDA to treat excessive daytime sleepiness and cataplexy in narcolepsy. The distinction between GHB and sodium oxybate should be noted. GHB is a Schedule I controlled substance due to the high abuse potential whereas sodium oxybate is Schedule III. Illicit GHB is said to produce euphoric, aphrodisiac and relaxing effects [74] and is considered one of the most popular party drugs. It also causes amnesia and increased passivity that has been used to aid criminal activity (e.g., "date rape"). However, in general, the problems related to illicit GHB have been declining significantly since the turn of the century; nevertheless the risk associated with the illicit GHB seems to greatly exceed that of legally prescribed sodium oxybate [75]. Abuse and misuse complications of sodium oxybate are relatively rare according to the post marketing data [75, 76].

Its ability to restore slow wave sleep (SWS) [77] has led to a series of trials to evaluate the efficacy of sodium oxybate for treating FMS and an application to the FDA. An early small, crossover RCT [78] showed that sodium oxybate $6 \mathrm{~g}$ a day at bedtime for 4 weeks significantly improved pain, fatigue, and sleep (restored SWS) as compared to placebo. More recently, multicenter studies [79-81] have shown that sodium oxybate $4.5-6 \mathrm{~g}$ per night significantly improved clinical pain and

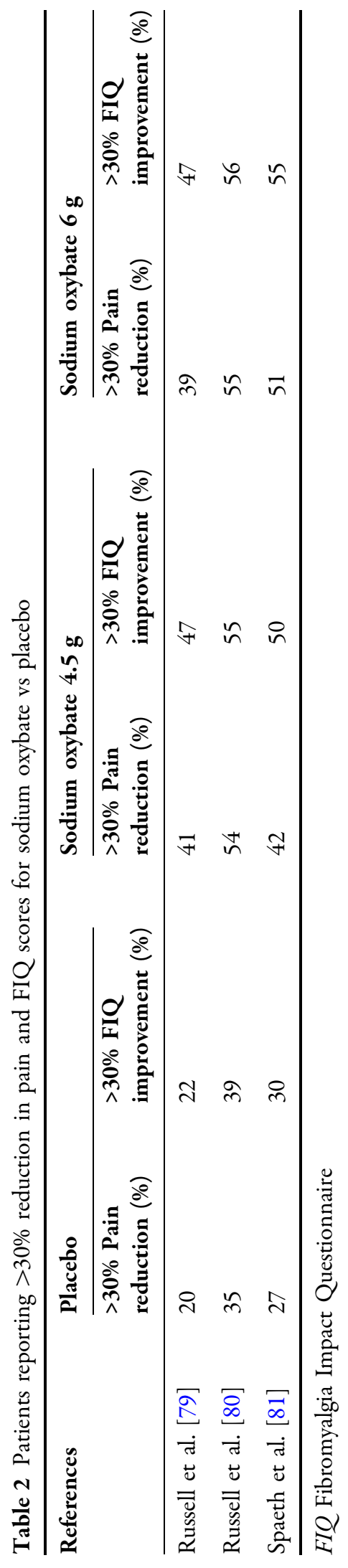


FMS-related symptoms relative to placebo. Table 2 [79-81] compares the percentage of patients who reported $>30 \%$ reduction in pain and FMS symptoms (total scores from the fibromyalgia impact questionnaire (FIQ) [82]) for sodium oxybate 4.5 and $6 \mathrm{~g}$ and placebo. The outcomes for the two sodium oxybate doses do not seem to differ. All studies found relatively high placebo response rates. The dropout rates were also relatively high due to adverse effects, particularly for the higher dose group (see Table 3 [79-81] for treatment completion rates for each study). Another concern regarding the use of sodium oxybate is its very short elimination half-life of approximately $30 \mathrm{~min}$ to $1 \mathrm{~h}$ [83]. For this reason, the dose was divided into two half doses, and the patients were required take a half dose at bedtime and wake up $2.5-4 \mathrm{~h}$ after bedtime to take another half dose. Interrupting the sleep of patients with existing sleep disturbance seems rather counterproductive [84]. Nevertheless, a polysomnographic study [85] demonstrated that sodium oxybate $6 \mathrm{~g}$ per night in a divided dose led to a significant improvement in the sleep measures in FMS, including total sleep time, waking after sleep onset, slow and wave sleep time.

The application for the FDA approval of sodium oxybate for treating FMS was denied in 2010. The advisory committee [86] concluded that the efficacy data, although promising, do

Table 3 Percentage of patients completing treatment in randomized controlled trials evaluating sodium oxybate

\begin{tabular}{llll}
\hline References & Placebo & $\begin{array}{l}\text { Sodium } \\
\text { oxybate 4.5 g }\end{array}$ & $\begin{array}{l}\text { Sodium } \\
\text { oxybate 6 g }\end{array}$ \\
\hline Russell et al. [79] & 81 & 88 & 67 \\
Russell et al. [80] & 61 & 65 & 57 \\
Spaeth et al. [81] & 70 & 65 & 61 \\
\hline
\end{tabular}

not show superior results to currently approved medications. They also expressed significant concern with the safety issues of the drug, with a potential for abuse and misuse with serious consequences. They felt that adequate safety measures were not available at the time.

Tricyclics and Other Antidepressants Early studies have shown that low dose amitriptyline and cyclobenzaprine, two tricyclic compounds, have beneficial effects on FMS symptoms. A meta-analysis [87] demonstrates that these agents help to reduce pain, fatigue, and sleep disturbance in FMS. However, there seems to be a large individual variation in the treatment response, and it has been estimated [88] that approximately 30\% of patients may benefit from tricyclics. The introduction of selective serotonin reuptake inhibitors (SSRIs) was received with much enthusiasm as they were considered to be a safer alternative to TCAs and could regulate serotonin reuptake. However, the results from RCTs were marginal for improving pain, sleep and mood in FMS patients $[89,90]$, even with a flexible dose [91].

Analgesics Corticosteroids were one of the first classes of medications to be tested for FMS; however, a double-blind RCT evaluating prednisone showed no clinical benefit [92]. Common over-the-counter analgesics such as non-steroidal anti-inflammatory drugs, although widely used by FMS patients, also do not appear to have any appreciable benefit [93]. The use of opioid analgesics in FMS does not seem to be very common [94], and they are generally not recommended for treating FMS, due to the lack of demonstrated efficacy [95]. Tramadol with the combined actions of weak opioid and norepinephrine and serotonin reuptake inhibitor (SNRI) effects has shown 
reduced pain and better functioning in a RCT [96]. The results are promising but need to be replicated.

Sedatives Benzodiazepine and nonbenzodiazepine hypnotics are commonly used to treat FMS patients, often targeting sleep and anxiety. However, controlled studies failed to demonstrate significant benefit [93, 97]. It has also to be argued that hypnotics/sedatives should not be used chronically due to potential complications and tolerance [98].

Dopamine Agonists There have been a few small studies evaluating the efficacy of dopamine agonists that are commonly used to treat Parkinson's disease and restless leg syndrome. A double-blind RCT [99] testing pramipexole for 14 weeks showed significant improvement in FMS symptoms relative to placebo. These preliminary results need to be replicated in a larger trial.

Cannabinoids Cannabinoids have recently emerged as an analgesic option for various pain conditions. A synthetic cannabinoid (nabilone) has been approved by the FDA for use as a second-line treatment for chemotherapy-induced nausea and vomiting. An early retrospective chart review study [100] of 20 patients with non-cancer chronic pain found some improvement in pain and sleep, suggesting a potential benefit for chronic pain patients in general as an analgesic. In the first double-blind RCT [101], 40 FMS patients received either placebo or nabilone (titrated to $1 \mathrm{mg}$ twice daily) for 4 weeks. The nabilone group showed significant decrease in pain and FIQ score relative to the placebo group at the post-treatment assessment, although the benefit seemed to disappear at the 8-week follow-up. The nabilone group had a greater dropout rate $(25 \%)$ versus the placebo group (10\%) and reported more drowsiness (50\%), dry mouth (30\%) and vertigo (27\%). Ware et al. [102] compared nabilone to amitriptyline in a crossover trial where patients received a 2 -week trial of each drug with a 2-week washout in between. Adverse effects (dizziness, nausea, dry mouth, drowsiness) were more prominent with nabilone. The two drugs showed a comparative decrease in sleep disturbance, although it is not clear whether there was a between-group difference in the degree of benefit. The groups did not differ with regard to the other FMSrelated symptoms, although it was not clear whether they showed any improvement with either treatment. Unfortunately, recruitment was difficult, with approximately half of patients who were approached declining to participate, making it difficult to ascertain the representability of the study sample. A systematic review of cannabinoids for treating non-cancer chronic pain [103] suggests that they are safe and may have some modest benefit for FMS, although the results are very preliminary at this point. The issues of longterm benefit and adverse effects need to be thoroughly investigated.

\section{Non-Pharmacologic Options}

\section{Exercise}

Physical deconditioning is common in FMS patients. Generally, incorporation of some physical fitness program as a part of FMS treatment is considered essential. The literature indicates that the efficacy of exercise seems to depend upon the content and intensity of the program. Generally, submaximal aerobic exercise, along with strengthening and stretching elements, is beneficial in reducing symptoms and hyperalgesic response [104, 105]. At least a 
moderate level of exercise intensity seems to be needed to derive clinical benefit but low intensity exercise tends to yield limited benefit [106]. Unfortunately, it is not easy to implement relatively vigorous exercise for FMS patients, as many patients are exercise-intolerant. The general recommendations for providing exercise therapy include (1) starting at a low level where patients can engage without significant distress, (2) gradual increase of the intensity level, (3) incorporating different types of exercise, and (4) reduction of exercise intensity/duration, while maintaining the frequency of exercise, if not tolerated [106, 107].

\section{Behavioral/Complementary Modalities}

Several behavioral modalities that are commonly used to treat chronic pain patients have been evaluated, although the methodological constraints and variations across studies make the quality of evidence rather weak. Generally, inconsistent and modest effects have been reported with hypnosis and biofeedback [108, 109]. Mindfulness-based stress reduction (MBSR) is an increasingly popular approach to treat various chronic illnesses. For FMS, an early study [110] showed some promising reduction in pain and symptoms with MBSR training relative to a control group. However, a subsequent 3-arm study comparing MBSR training to both active control (supportive group with relaxation training) and wait list group failed to show any benefit [111]. Complementary and alternative (CAM) approaches are very popular with FMS patients. Unfortunately, many of the trials are not well-controlled or included small numbers of patients. Because of the methodologic concerns, the level of clinical benefit of CAM therapies for FMS cannot be determined from the current literature [112].
One of the most widely accepted behavioral therapy modalities is cognitive-behavioral therapy (CBT). Clinical trials testing CBT alone, however, tend to be small with various methodologic problems, making it difficult to interpret its efficacy. In general, CBT monotherapy is effective in improving the target variables (e.g., maladaptive cognition, mood, quality of life; QOL) [113-115] although the effects on the primary FMS symptoms may be limited. The efficacy seems to improve when CBT is included as a part of a multidisciplinary treatment program (see below).

\section{Multidisciplinary Treatment}

Given the complex, multifactorial nature of FMS, it is reasonable to assume that multimodal therapy targeting multiple factors may work well. However, systematic evaluation of studies evaluating multidisciplinary therapy for FMS is difficult because of the wide variability in the parameters of the treatment. Unfortunately, the lack of methodological vigor is not uncommon, reflecting the difficulty of conducting costly, logistically demanding trials using multimodal approaches.

Although there are some other variations, a typical trial testing a multidisciplinary approach includes education, exercise and psychological (typically cognitive behavioral) therapy. Programs aimed at acquisition of coping and pain management skills seem to provide better results than those that mostly aim to provide information/education [109]. A systematic review [116] points to the methodological weakness, yet provides some evidence of the effectiveness of the approach for various chronic pain conditions including FMS. The effectiveness seems to last beyond the therapy; reduction in pain and other symptoms was observed 12 months later [117]. A recent 
recommendation [118] by FMS experts strongly emphasizes the importance of educating patients, establishing working goals, and applying multimodal therapy approaches consisting of education, medications, exercise and CBT. There has only been one published study thus far that specifically tested the combination of CBT with medication [119]. In this trial, patients were randomized to a combination of CBT and milnacipran, drug monotherapy or CBT alone. The results suggest that the combination approach and CBT monotherapy were equally beneficial in reducing symptoms, i.e., milnacipran added very little to the clinical benefit of CBT.

\section{FUTURE DIRECTIONS}

Despite extensive efforts to delineate an effective treatment in the past 30 years, FMS continues to be a very difficult chronic pain condition to treat. Some prominent challenges in interpreting the literature are the poor quality of the methodology, particularly for non-pharmacologic approaches, and the large placebo effects in drug trials. Furthermore, although clinical benefits are typically evaluated by statistical comparisons of the treatment groups, there remains a large within-group variation in treatment response. This makes it nearly impossible to know whether a particular patient would benefit from a certain treatment. Well-controlled RCTs could indicate whether the treatment would likely benefit an average patient, but not a particular patient.

Recently, novel approaches have been proposed to expand our ability to evaluate the therapeutic effects for each patient. For example, the new statistical framework, dynamically modified outcomes (DYNAMO) [120] could estimate the causal effects of therapy for each patient and help determine the true effects of therapy for a specific patient. The individually customized statistical causal model can then provide guidance for matching treatment to patients. Similarly, the sequential multiple assignment randomization trials (SMART) [121] approach, in which patients undergo multiple randomization to sequential treatments, may provide adaptive analyses of efficacy at the individual patient level that could help establish the most effective clinical algorithm. Given the heterogeneous treatment responses, these approaches may greatly enhance the ability to produce clinically significant and relevant evidence in FMS clinical research.

The heterogeneity of FMS patients is not limited to treatment response. A number of reports note heterogeneity with respect to a range of the disease parameters including history and disease expression [122], suggesting the importance of patient-centered, individualized treatment planning. One of the important, yet often neglected, aspects is the variation in symptoms over time. Negative $\mathrm{mood} / \mathrm{stress}$, poor sleep, and fatigue often trigger an overall symptom exacerbation [123]. Daily longitudinal analyses of the symptom fluctuation suggest that worsening in one symptom often intensifies other symptoms, although the degree to which one symptom affects another varies across individuals [124]. In other words, although all symptoms influence other symptoms to some level, each person may have one symptom that exerts more influence than others, presenting a unique causal covariation pattern for this particular patient. If we can identify which symptom drives others in a patient, treatment certainly can be customized to prioritize a particular target symptom. 
Many clinical trials face the dilemma of balancing the internal versus external validity. Clearly, well-controlled studies are needed: however, by making the study "clean" one often creates an unrealistic clinical situation where the results may not apply to the population at large. In the real world, FMS patients vary in a range of clinical variables with often complicated issues such as mood disorders and polypharmacy; however, in the current clinical research environment, such complication is not appreciated and is often minimized by patient selection criteria. How we can delineate an evidence-based approach that is truly based on reality is a lingering question with no easy answers. One approach may be to test an agent/method of therapy to be combined with another that has yielded relatively good outcomes. For example, the pharmacologic trials are mostly restricted to testing the agents alone against placebo. Drugs with promising results can be combined with exercise or a multidisciplinary approach. The recent study by Ang et al. [119] of a combination of CBT and milnacipran is one of the first published reports and more should be done employing this type of approach. FMS clinical research will require going beyond the traditional RCT models and applying innovative and novel conceptual and methodologic ventures.

\section{ACKNOWLEDGMENTS}

No funding or sponsorship was received for this study or publication of this article.

Dr. Okifuji is the guarantor for this article, and takes responsibility for the integrity of the work as a whole.

Conflict of interest. Dr. Okifuji and Dr. Hare declare no conflicts of interest.
Open Access. This article is distributed under the terms of the Creative Commons Attribution Noncommercial License which permits any noncommercial use, distribution, and reproduction in any medium, provided the original author(s) and the source are credited.

\section{REFERENCES}

1. Wolfe F, Smythe HA, Yunus MB, Bennett RM, Bombardier C, Goldenberg DL, et al. The American college of rheumatology 1990 criteria for the classification of fibromyalgia. Report of the Multicenter Criteria Committee [see comments]. Arthr Rheum. 1990;33(2):160-72.

2. White KP, Speechley M, Harth M, Ostbye T. The London fibromyalgia epidemiology study: direct health care costs of fibromyalgia syndrome in London. Canada. J Rheumatol. 1999;26(4):885-9.

3. Lawrence RC, Felson DT, Helmick CG, Arnold LM, Choi H, Deyo RA, et al. Estimates of the prevalence of arthritis and other rheumatic conditions in the United States. Part II. Arthr Rheum. 2008;58(1): 26-35.

4. Simons DG. Muscle pain syndromes-Part I. Am J Phys Med. 1975;54(6):289-311.

5. Gowers W. Lumbago: its lessons and analogues. BMJ. 1904;1:117-21.

6. Bennett RM. Fibrositis: misnomer for a common rheumatic disorder. West J Med. 1981;134(5): 405-13.

7. Yunus M, Masi AT, Calabro JJ, Miller KA, Feigenbaum SL. Primary fibromyalgia (fibrositis): clinical study of 50 patients with matched normal controls. Semin Arthr Rheum. 1981;11(1):151-71.

8. Smythe H. Nonarticular rheumatism and the fibrositis syndrome. In: Hollander L, editor. Arthritis and allied conditions; a textbook of rheumatology. 8th ed. Philadelphia: Lea \& Febiger; 1972. p. $874-84$.

9. Yunus MB, Masi AT, Aldag JC. Preliminary criteria for primary fibromyalgia syndrome (PFS): multivariate analysis of a consecutive series of PFS, other pain patients, and normal subjects. Clin Exp Rheumatol. 1989;7(1):63-9.

10. McCarberg B, Barkin RL, Wright JA, Cronan TA, Groessl E, Schmidt SM. Tender points as predictors of distress and the pharmacologic management of 
fibromyalgia syndrome. Am J Ther. 2003;10(3): 176-92.

11. Petzke F, Gracely RH, Park KM, Ambrose K, Clauw DJ. What do tender points measure? Influence of distress on 4 measures of tenderness. J Rheumatol. 2003;30(3):567-74.

12. Wolfe F. The relation between tender points and fibromyalgia symptom variables: evidence that fibromyalgia is not a discrete disorder in the clinic. Ann Rheum Dis. 1997;56(4):268-71.

13. Woolf CJ. Central sensitization: implications for the diagnosis and treatment of pain. Pain. 2011;152(3 Suppl):S2-15.

14. Clauw DJ, Crofford LJ. Chronic widespread pain and fibromyalgia: what we know, and what we need to know. Best Pract Res Clin Rheumatol. 2003;17(4): 685-701.

15. Fitzcharles MA, Boulos P. Inaccuracy in the diagnosis of fibromyalgia syndrome: analysis of referrals. Rheumatology (Oxford). 2003;42(2):263-7.

16. Katz RS, Wolfe F, Michaud K. Fibromyalgia diagnosis: a comparison of clinical, survey, and American college of rheumatology criteria. Arthr Rheum. 2006;54(1):169-76.

17. Wolfe F, Clauw DJ, Fitzcharles MA, Goldenberg DL, Katz RS, Mease P, et al. The American college of rheumatology preliminary diagnostic criteria for fibromyalgia and measurement of symptom severity. Arthr Care Res (Hoboken). 2010;62(5): 600-10.

18. Arroyo JF, Cohen ML. Abnormal responses to electrocutaneous stimulation in fibromyalgia [see comments]. J Rheumatol. 1993;20(11):1925-31.

19. Gibson SJ, Littlejohn GO, Gorman MM, Helme RD, Granges G. Altered heat pain thresholds and cerebral event-related potentials following painful $\mathrm{CO}_{2}$ laser stimulation in subjects with fibromyalgia syndrome. Pain. 1994;58(2):185-93.

20. Kosek E, Hansson P. Modulatory influence on somatosensory perception from vibration and heterotopic noxious conditioning stimulation (HNCS) in fibromyalgia patients and healthy subjects. Pain. 1997;70(1):41-51.

21. Petzke F, Clauw DJ, Ambrose K, Khine A, Gracely RH. Increased pain sensitivity in fibromyalgia: effects of stimulus type and mode of presentation. Pain. 2003;105(3):403-13.

22. Staud R, Price DD, Robinson ME, Mauderli AP, Vierck CJ. Maintenance of windup of second pain requires less frequent stimulation in fibromyalgia patients compared to normal controls. Pain. 2004;110(3):689-96.

23. Gracely RH, Petzke F, Wolf JM, Clauw DJ. Functional magnetic resonance imaging evidence of augmented pain processing in fibromyalgia. Arthr Rheum. 2002;46(5):1333-43.

24. Lorenz J, Grasedyck K, Bromm B. Middle and long latency somatosensory evoked potentials after painful laser stimulation in patients with fibromyalgia syndrome. Electroencephalogr Clin Neurophysiol. 1996;100(2):165-8.

25. Yunus MB, Dailey JW, Aldag JC, Masi AT, Jobe PC. Plasma tryptophan and other amino acids in primary fibromyalgia: a controlled study. J Rheumatol. 1992;19(1):90-4.

26. Wolfe F, Russell IJ, Vipraio G, Ross K, Anderson J. Serotonin levels, pain threshold, and fibromyalgia symptoms in the general population. J Rheumatol. 1997;24(3):555-9.

27. Norregaard J, Bulow PM, Mehlsen J, DanneskioldSamsoe B. Biochemical changes in relation to a maximal exercise test in patients with fibromyalgia. Clin Physiol. 1994;14(2):159-67.

28. Russell IJ, Michalek JE, Vipraio GA, Fletcher EM, Javors MA, Bowden CA. Platelet 3H-imipramine uptake receptor density and serum serotonin levels in patients with fibromyalgia/fibrositis syndrome [see comments]. J Rheumatol. 1992;19(1):104-9.

29. Malt EA, Olafsson S, Aakvaag A, Lund A, Ursin H. Altered dopamine D2 receptor function in fibromyalgia patients: a neuroendocrine study with buspirone in women with fibromyalgia compared to female population based controls. J Affect Disord. 2003;75(1):77-82.

30. Wood PB, Patterson JC 2nd, Sunderland JJ, Tainter $\mathrm{KH}$, Glabus MF, Lilien DL. Reduced presynaptic dopamine activity in fibromyalgia syndrome demonstrated with positron emission tomography: a pilot study. J Pain. 2007;8(1):51-8.

31. Kadetoff D, Kosek E. Evidence of reduced sympathoadrenal and hypothalamic-pituitary activity during static muscular work in patients with fibromyalgia. J Rehabil Med. 2010;42(8):765-72.

32. van Denderen JC, Boersma JW, Zeinstra P, Hollander AP, van Neerbos BR. Physiological effects of exhaustive physical exercise in primary fibromyalgia syndrome (PFS): is PFS a disorder of neuroendocrine reactivity? Scand J Rheumatol. 1992;21(1):35-7.

33. Loevinger BL, Muller D, Alonso C, Coe CL. Metabolic syndrome in women with chronic pain. Metabolism. 2007;56(1):87-93. 
34. Hamaty D, Valentine JL, Howard R, Howard CW, Wakefield V, Patten MS. The plasma endorphin, prostaglandin and catecholamine profile of patients with fibrositis treated with cyclobenzaprine and placebo: a 5-month study. J Rheumatol Suppl. 1989;19:164-8.

35. Adler GK, Kinsley BT, Hurwitz S, Mossey CJ, Goldenberg DL. Reduced hypothalamic-pituitary and sympathoadrenal responses to hypoglycemia in women with fibromyalgia syndrome. Am J Med. 1999;106(5):534-43.

36. Crofford LJ, Pillemer SR, Kalogeras KT, Cash JM, Michelson D, Kling MA, et al. Hypothalamic-pituitary-adrenal axis perturbations in patients with fibromyalgia. Arthr Rheum. 1994;37(11):1583-92.

37. Martinez-Lavin M. Biology and therapy of fibromyalgia. Stress, the stress response system, and fibromyalgia. Arthr Res Ther. 2007;9(4):216.

38. Di Franco M, Iannuccelli C, Valesini G. Neuroendocrine immunology of fibromyalgia. Ann N Y Acad Sci. 2010;1193:84-90.

39. Staud R. Heart rate variability as a biomarker of fibromyalgia syndrome. Fut Rheumatol. 2008;3(5): 475-83.

40. Di Franco M, Iannuccelli C, Alessandri C, Paradiso M, Riccieri V, Libri F, et al. Autonomic dysfunction and neuropeptide $\mathrm{Y}$ in fibromyalgia. Clin Exp Rheumatol. 2009;27(5 Suppl 56):S75-8.

41. Vargas-Alarcon G, Fragoso JM, Cruz-Robles D, Vargas A, Martinez A, Lao-Villadoniga JI, et al. Association of adrenergic receptor gene polymorphisms with different fibromyalgia syndrome domains. Arthr Rheum. 2009;60(7): 2169-73.

42. Light KC, White AT, Tadler S, Iacob E, Light AR. Genetics and gene expression involving stress and distress pathways in fibromyalgia with and without comorbid chronic fatigue syndrome. Pain Res Treat. 2012;2012:1-13.

43. Xiao Y, He W, Russell IJ. Genetic polymorphisms of the beta2-adrenergic receptor relate to guanosine protein-coupled stimulator receptor dysfunction in fibromyalgia syndrome. J Rheumatol. 2011;38(6): 1095-103.

44. Light AR, Bateman L, Jo D, Hughen RW, Vanhaitsma TA, White AT, et al. Gene expression alterations at baseline and following moderate exercise in patients with chronic fatigue syndrome and fibromyalgia syndrome. J Intern Med. 2012;271(1):64-81.
45. Light AR, White AT, Hughen RW, Light KC. Moderate exercise increases expression for sensory, adrenergic, and immune genes in chronic fatigue syndrome patients but not in normal subjects. J Pain. 2009;10(10):1099-112.

46. Bengtsson A, Henriksson KG, Larsson J. Muscle biopsy in primary fibromyalgia. Light-microscopical and histochemical findings. Scand J Rheumatol. 1986;15(1):1-6.

47. Drewes AM, Andreasen A, Schroder HD, Hogsaa B, Jennum P. Pathology of skeletal muscle in fibromyalgia: a histo-immuno-chemical and ultrastructural study. $\mathrm{Br}$ J Rheumatol. 1993;32(6):479-83.

48. Bengtsson A, Henriksson KG. The muscle in fibromyalgia-a review of Swedish studies. J Rheumatol Suppl. 1989;19:144-9.

49. Park JH, Phothimat P, Oates CT, Hernanz-Schulman $\mathrm{M}$, Olsen NJ. Use of P-31 magnetic resonance spectroscopy to detect metabolic abnormalities in muscles of patients with fibromyalgia. Arthr Rheum. 1998;41(3):406-13.

50. Sprott H, Rzanny R, Reichenbach JR, Kaiser WA, Hein G, Stein G. 31P magnetic resonance spectroscopy in fibromyalgic muscle. Rheumatology (Oxford). 2000;39(10):1121-5.

51. Elvin A, Siosteen AK, Nilsson A, Kosek E. Decreased muscle blood flow in fibromyalgia patients during standardised muscle exercise: a contrast media enhanced colour Doppler study. Eur J Pain. 2006;10(2):137-44.

52. Bennett RM, Clark SR, Campbell SM, Ingram SB, Burckhardt CS, Nelson DL, et al. Symptoms of Raynaud's syndrome in patients with fibromyalgia. A study utilizing the Nielsen test, digital photoplethysmography, and measurements of platelet alpha 2-adrenergic receptors. Arthr Rheum. 1991;34(3):264-9.

53. Ge HY, Nie H, Madeleine P, Danneskiold-Samsoe B, Graven-Nielsen T, Arendt-Nielsen L. Contribution of the local and referred pain from active myofascial trigger points in fibromyalgia syndrome. Pain. 2009;147(1-3):233-40.

54. Alonso-Blanco C, Fernandez-de-las-Penas C, Morales-Cabezas M, Zarco-Moreno P, Ge HY, Florez-Garcia M. Multiple active myofascial trigger points reproduce the overall spontaneous pain pattern in women with fibromyalgia and are related to widespread mechanical hypersensitivity. Clin J Pain. 2011;27(5):405-13.

55. Staud R. Peripheral pain mechanisms in chronic widespread pain. Best Pract Res Clin Rheumatol. 2011;25(2):155-64. 
56. Arnold LM, Russell IJ, Diri EW, Duan WR, Young JP Jr, Sharma U, et al. A 14-week, randomized, double-blinded, placebo-controlled monotherapy trial of pregabalin in patients with fibromyalgia. J Pain. 2008;9(9):792-805.

57. Hauser W, Bernardy K, Uceyler N, Sommer C. Treatment of fibromyalgia syndrome with gabapentin and pregabalin-a meta-analysis of randomized controlled trials. Pain. 2009;145(1-2): 69-81.

58. Straube S, Derry S, Moore RA, McQuay HJ. Pregabalin in fibromyalgia: meta-analysis of efficacy and safety from company clinical trial reports. Rheumatology (Oxford). 2010;49(4): 706-15.

59. Arnold LM, Emir B, Murphy TK, Zeiher BG, Pauer L, Scott G, et al. Safety profile and tolerability of up to 1 year of pregabalin treatment in 3 open-label extension studies in patients with fibromyalgia. Clin Ther. 2012;34(5):1092-102.

60. Arnold LM, Rosen A, Pritchett YL, D'Souza DN, Goldstein DJ, Iyengar S, et al. A randomized, double-blind, placebo-controlled trial of duloxetine in the treatment of women with fibromyalgia with or without major depressive disorder. Pain. 2005;119(1-3):5-15.

61. Arnold LM, Lu Y, Crofford LJ, Wohlreich M, Detke MJ, Iyengar S, et al. A double-blind, multicenter trial comparing duloxetine with placebo in the treatment of fibromyalgia patients with or without major depressive disorder. Arthr Rheum. 2004;50(9):2974-84.

62. Russell IJ, Mease PJ, Smith TR, Kajdasz DK, Wohlreich MM, Detke MJ, et al. Efficacy and safety of duloxetine for treatment of fibromyalgia in patients with or without major depressive disorder: results from a 6-month, randomized, double-blind, placebo-controlled, fixed-dose trial. Pain. 2008;136(3):432-44.

63. Arnold LM, Clauw DJ, Wohlreich MM, Wang F, Ahl J, Gaynor PJ, et al. Efficacy of duloxetine in patients with fibromyalgia: pooled analysis of 4 placebocontrolled clinical trials. Prim Care Companion J Clin Psychiatry. 2009;11(5):237-44.

64. Arnold LM, Wang F, Ahl J, Gaynor PJ, Wohlreich MM. Improvement in multiple dimensions of fatigue in patients with fibromyalgia treated with duloxetine: secondary analysis of a randomized, placebo-controlled trial. Arthr Res Ther. 2011;13(3):R86-93.

65. Mease PJ, Russell IJ, Kajdasz DK, Wiltse CG, Detke MJ, Wohlreich MM, et al. Long-term safety, tolerability, and efficacy of duloxetine in the treatment of fibromyalgia. Semin Arthr Rheum. 2010;39(6):454-64.

66. Arnold LM, Zhang S, Pangallo BA. Efficacy and safety of duloxetine $30 \mathrm{mg} / \mathrm{d}$ in patients with fibromyalgia: a randomized, double-blind, placebo-controlled study. Clin J Pain. 2012;28(9):775-81.

67. Vitton O, Gendreau M, Gendreau J, Kranzler J, Rao SG. A double-blind placebo-controlled trial of milnacipran in the treatment of fibromyalgia. Hum Psychopharmacol. 2004;19(Suppl 1):S27-35.

68. Clauw DJ, Mease P, Palmer RH, Gendreau RM, Wang Y. Milnacipran for the treatment of fibromyalgia in adults: a 15-week, multicenter, randomized, double-blind, placebo-controlled, multiple-dose clinical trial. Clin Ther. 2008;30(11):1988-2004.

69. Mease PJ, Clauw DJ, Gendreau RM, Rao SG, Kranzler $\mathrm{J}$, Chen W, et al. The efficacy and safety of milnacipran for treatment of fibromyalgia. a randomized, double-blind, placebo-controlled trial. J Rheumatol. 2009;36(2):398-409.

70. Geisser ME, Palmer RH, Gendreau RM, Wang Y, Clauw DJ. A pooled analysis of two randomized, double-blind, placebo-controlled trials of milnacipran monotherapy in the treatment of fibromyalgia. Pain Pract. 2011;11(2):120-31.

71. Arnold LM, Palmer RH, Ma Y. A 3-year, open-label, flexible-dosing study of milnacipran for the treatment of fibromyalgia. Clin J Pain. 2013 [Epub ahead of print].

72. Hauser W, Petzke F, Sommer C. Comparative efficacy and harms of duloxetine, milnacipran, and pregabalin in fibromyalgia syndrome. J Pain. 2010;11(6):505-21.

73. Hauser W, Sarzi-Puttini P, Tolle TR, Wolfe F. Placebo and nocebo responses in randomised controlled trials of drugs applying for approval for fibromyalgia syndrome treatment: systematic review and meta-analysis. Clin Exp Rheumatol. 2012;30(6 Suppl 74):78-87.

74. Barker JC, Harris SL, Dyer JE. Experiences of gamma hydroxybutyrate (GHB) ingestion: a focus group study. J Psychoactive Drugs. 2007;39(2):115-29.

75. Carter LP, Pardi D, Gorsline J, Griffiths RR. Illicit gamma-hydroxybutyrate (GHB) and pharmaceutical sodium oxybate (Xyrem): differences in characteristics and misuse. Drug Alcohol Depend. 2009;104(1-2):1-10.

76. Wang YG, Swick TJ, Carter LP, Thorpy MJ, Benowitz NL. Sodium oxybate: updates and correction to 
previously published safety data. J Clin Sleep Med. 2011;7(4):415-6.

77. Pardi D, Black J. gamma-Hydroxybutyrate/sodium oxybate: neurobiology, and impact on sleep and wakefulness. CNS Drugs. 2006;20(12):993-1018.

78. Scharf MB, Baumann M, Berkowitz DV. The effects of sodium oxybate on clinical symptoms and sleep patterns in patients with fibromyalgia. J Rheumatol. 2003;30(5):1070-4.

79. Russell IJ, Perkins AT, Michalek JE. Sodium oxybate relieves pain and improves function in fibromyalgia syndrome: a randomized, double-blind, placebocontrolled, multicenter clinical trial. Arthr Rheum. 2009;60(1):299-309.

80. Russell IJ, Holman AJ, Swick TJ, Alvarez-Horine S, Wang YG, Guinta D. Sodium oxybate reduces pain, fatigue, and sleep disturbance and improves functionality in fibromyalgia: results from a 14-week, randomized, double-blind, placebo-controlled study. Pain. 2011;152(5): 1007-17.

81. Spaeth M, Bennett RM, Benson BA, Wang YG, Lai C, Choy EH. Sodium oxybate therapy provides multidimensional improvement in fibromyalgia: results of an international phase 3 trial. Ann Rheum Dis. 2012;71(6):935-42.

82. Burckhardt CS, Clark SR, Bennett RM. The fibromyalgia impact questionnaire: development and validation. J Rheumatol. 1991;18(5):728-33.

83. Food and Drug Administration. [cited 2013 04-03]; Xyrem $^{\circledR}$ (sodium oxybate)]. Available from: http:// www.fda.gov/ohrms/dockets/dockets/05n0479/05N0479-EC9-Attach-2.pdf.

84. Alarcon GS. Questioning the likelihood that sodium oxybate can be used to successfully treat fibromyalgia: comment on the article by Russell et al. Arthr Rheum. 2009;60(9):2854.

85. Moldofsky H, Inhaber NH, Guinta DR, AlvarezHorine SB. Effects of sodium oxybate on sleep physiology and sleep/wake-related symptoms in patients with fibromyalgia syndrome: a doubleblind, randomized, placebo-controlled study. J Rheumatol. 2010;37(10):2156-66.

86. Summary Minutes of the Joint Meeting of the Arthritis Advisory Committee and the Drug Safety and Risk Management Advisory Committee. Bethesda: FDA. 2010.

87. Arnold LM, Keck PE Jr, Welge JA. Antidepressant treatment of fibromyalgia. A meta-analysis and review. Psychosomatics. 2000;41(2):104-13.
88. Carette S, Bell MJ, Reynolds WJ, Haraoui B, McCain GA, Bykerk VP, et al. Comparison of amitriptyline, cyclobenzaprine, and placebo in the treatment of fibromyalgia. A randomized, double-blind clinical trial [see comments]. Arthr Rheum. 1994;37(1):32-40.

89. Goldenberg D, Mayskiy M, Mossey C, Ruthazer R, Schmid C. A randomized, double-blind crossover trial of fluoxetine and amitriptyline in the treatment of fibromyalgia. Arthr Rheum. 1996;39(11):1852-9.

90. Wolfe F, Cathey MA, Hawley DJ. A double-blind placebo controlled trial of fluoxetine in fibromyalgia. Scand J Rheumatol. 1994;23(5):255-9.

91. Arnold LM, Hess EV, Hudson JI, Welge JA, Berno SE, Keck PE Jr. A randomized, placebo-controlled, double-blind, flexible-dose study of fluoxetine in the treatment of women with fibromyalgia. Am J Med. 2002;112(3):191-7.

92. Clark S, Tindall E, Bennett RM. A double blind crossover trial of prednisone versus placebo in the treatment of fibrositis. J Rheumatol. 1985;12(5):980-3.

93. Russell IJ, Fletcher EM, Michalek JE, McBroom PC, Hester GG. Treatment of primary fibrositis/ fibromyalgia syndrome with ibuprofen and alprazolam. A double-blind, placebo-controlled study. Arthr Rheum. 1991;34(5):552-60.

94. Mease PJ, Dundon K, Sarzi-Puttini P. Pharmacotherapy of fibromyalgia. Best Pract Res Clin Rheumatol. 2011;25(2):285-97.

95. Ngian GS, Guymer EK, Littlejohn GO. The use of opioids in fibromyalgia. Int $\mathrm{J}$ Rheum Dis. 2011;14(1):6-11.

96. Bennett RM, Kamin M, Karim R, Rosenthal N. Tramadol and acetaminophen combination tablets in the treatment of fibromyalgia pain: a doubleblind, randomized, placebo-controlled study. Am J Med. 2003;114(7):537-45.

97. Moldofsky H, Lue FA, Mously C, Roth-Schechter B, Reynolds WJ. The effect of zolpidem in patients with fibromyalgia: a dose ranging, double blind, placebo controlled, modified crossover study. J Rheumatol. 1996;23(3):529-33.

98. Clauw DJ. Pharmacotherapy for patients with fibromyalgia. J Clin Psychiatry. 2008;69(Suppl 2):25-9.

99. Holman AJ, Myers RR. A randomized, double-blind, placebo-controlled trial of pramipexole, a dopamine agonist, in patients with fibromyalgia 
receiving concomitant medications. Arthr Rheum. 2005;52(8):2495-505.

100. Berlach DM, Shir Y, Ware MA. Experience with the synthetic cannabinoid nabilone in chronic noncancer pain. Pain Med. 2006;7(1):25-9.

101. Skrabek RQ, Galimova L, Ethans K, Perry D. Nabilone for the treatment of pain in fibromyalgia. J Pain. 2008;9(2):164-73.

102. Ware MA, Fitzcharles MA, Joseph L, Shir Y. The effects of nabilone on sleep in fibromyalgia: results of a randomized controlled trial. Anesth Analg. 2010;110(2):604-10.

103. Lynch ME, Campbell F. Cannabinoids for treatment of chronic non-cancer pain; a systematic review of randomized trials. $\mathrm{Br} \mathrm{J}$ Clin Pharmacol. 2011;72(5):735-44.

104. Kelley GA, Kelley KS, Jones DL. Efficacy and effectiveness of exercise on tender points in adults with fibromyalgia: a meta-analysis of randomized controlled trials. Arthritis. 2011;2011:125485.

105. Jones KD, Adams D, Winters-Stone K, Burckhardt CS. A comprehensive review of 46 exercise treatment studies in fibromyalgia (1988-2005). Health Qual Life Outcomes. 2006;4:67.

106. Busch AJ, Webber SC, Brachaniec M, Bidonde J, Bello-Haas VD, Danyliw AD, et al. Exercise therapy for fibromyalgia. Curr Pain Headache Rep. 2011;15(5):358-67.

107. Jones KD, Burckhardt CS, Deodhar AA, Perrin NA, Hanson GC, Bennett RM. A six-month randomized controlled trial of exercise and pyridostigmine in the treatment of fibromyalgia. Arthr Rheum. 2008;58(2):612-22.

108. Bernardy K, Fuber N, Klose P, Hauser W. Efficacy of hypnosis/guided imagery in fibromyalgia syndrome-a systematic review and meta-analysis of controlled trials. BMC Musculoskelet Disord. 2011;12:133-43.

109. Okifuji A, Hare BD. Mangement of musculoskeletal pain. In: Ebert MH, Kerns RD, editors. Behavioral and Pharmacologic Pain Management: Cambridge: Cambridge University Press; 2010.

110. Grossman P, Tiefenthaler-Gilmer U, Raysz A, Kesper U. Mindfulness training as an intervention for fibromyalgia: evidence of postintervention and 3 -year follow-up benefits in well-being. Psychother Psychosom. 2007;76(4):226-33.

111. Schmidt S, Grossman P, Schwarzer B, Jena S, Naumann J, Walach H. Treating fibromyalgia with mindfulness-based stress reduction: results from a 3-armed randomized controlled trial. Pain. 2011;152(2):361-9.

112. Adams N, Sim J. Rehabilitation approaches in fibromyalgia. Disabil Rehabil. 2005;27(12):711-23.

113. Alda M, Luciano JV, Andres E, Serrano-Blanco A, Rodero B, del Hoyo YL, et al. Effectiveness of cognitive behaviour therapy for the treatment of catastrophisation in patients with fibromyalgia: a randomised controlled trial. Arthr Res Ther. 2011;13(5):R173-85.

114. Wicksell RK, Kemani M, Jensen K, Kosek E, Kadetoff $\mathrm{D}$, Sorjonen K, et al. Acceptance and commitment therapy for fibromyalgia: a randomized controlled trial. Eur J Pain. 2013;17(4):599-611.

115. Bernardy K, Fuber N, Kollner V, Hauser W. Efficacy of cognitive-behavioral therapies in fibromyalgia syndrome-a systematic review and metaanalysis of randomized controlled trials. J Rheumatol. 2010;37(10):1991-2005.

116. Scascighini L, Toma V, Dober-Spielmann S, Sprott H. Multidisciplinary treatment for chronic pain: a systematic review of interventions and outcomes. Rheumatology (Oxford). 2008;47(5):670-8.

117. Martin J, Torre F, Padierna A, Aguirre U, Gonzalez N, Garcia S, et al. Six-and 12-month follow-up of an interdisciplinary fibromyalgia treatment programme: results of a randomised trial. Clin Exp Rheumatol. 2012;30(6 Suppl 74):103-11.

118. Arnold LM, Clauw DJ, Dunegan LJ, Turk DC. A framework for fibromyalgia management for primary care providers. Mayo Clin Proc. 2012;87(5):488-96. 
119. Ang DC, Jensen MP, Steiner JL, Hilligoss J, Gracely $\mathrm{RH}$, Saha C. Combining cognitive-behavioral therapy and milnacipran for fibromyalgia: a feasibility randomized-controlled trial. Clin J Pain. 2013;29(9):747-54.

120. Donaldson GW, Nakamura Y, Moinpour C. Mediators, moderators, and modulators of causal effects in clinical trials-dynamically modified outcomes (DYNAMO) in health-related quality of life. Qual Life Res. 2009;18(2):137-45.

121. Almirall D, Compton SN, Gunlicks-Stoessel M, Duan N, Murphy SA. Designing a pilot sequential multiple assignment randomized trial for developing an adaptive treatment strategy. Stat Med. 2012;31(17):1887-902.
122. Wilson HD, Starz TW, Robinson JP, Turk DC. Heterogeneity within the fibromyalgia population: theoretical implications of variable tender point severity ratings. J Rheumatol. 2009;36(12):2795-801.

123. Okifuji A, Turk DC. Stress and psychophysiological dysregulation in patients with fibromyalgia syndrome. Appl Psychophysiol Biofeedback. 2002;27(2):129-41.

124. Okifuji A, Bradshaw DH, Donaldson GW, Turk DC. Sequential analyses of daily symptoms in women with fibromyalgia syndrome. J Pain. 2011;12(1):84-93. 